\title{
Aspiration and outflow of the intermediate water in the East/Japan Sea through the Tsugaru Strait
}

\author{
Jong Jin Park, ${ }^{1}$ Kuh Kim, ${ }^{2}$ and Joon-Yong Yang ${ }^{3}$ \\ Received 12 December 2007; revised 14 February 2008; accepted 21 February 2008; published 1 April 2008.
}

[1] Outflow of the intermediate water in the East/Japan Sea through the Tsugaru Strait is inferred from the fact that profiling floats deployed below the sill depth in the central East/Japan Sea moved out to the Northwest Pacific Ocean through the Strait. Careful analysis of the float trajectories reveals that profiling floats parked at $350 \mathrm{~m}, 700 \mathrm{~m}$, and $800 \mathrm{~m}$ could be uplifted from depths below the sill of the Tsugaru Strait and moved over the $140 \mathrm{~m}$ deep sill with a probability close to $100 \%$. Application of an analytical model for the Bernoulli suction shows that intermediate waters can be aspirated over the sill depth of the Tsugaru Strait in late winter. Citation: Park, J. J., K. Kim, and J.-Y. Yang (2008), Aspiration and outflow of the intermediate water in the East/Japan Sea through the Tsugaru Strait, Geophys. Res. Lett., 35, L07601, doi:10.1029/2007GL032981.

\section{Introduction}

[2] The East/Japan Sea (hereafter EJS) is a deep semienclosed marginal basin, which is connected with the North Pacific and the Okhotsk Sea through the Korea/Tsushima, Tsugaru, Soya, and Tatar Straits (Figure 1), whose sill depths are shallower than $140 \mathrm{~m}$ or less. The Tsushima Current of warm and saline water flows into the EJS through the Korea/Tsushima Strait and out through the Tsugaru and Soya Strait. The spatial structure and annual variation of the currents in the Tsugaru Strait have been recently revealed by ADCP measurements [Onishi et al., 2004], which indicate that it is the major outlet in terms of volume transport.

[3] The EJS possesses its own deep water which is formed through convective overturning in wintertime and comprises various water masses just like the open oceans [Kim et al., 2004]. The water masses formed in the northern part of the EJS fill up below the thermocline in the entire EJS including the southern part. As the depth of the permanent thermocline in the southern part of the EJS is about $200 \mathrm{~m}$ which is deeper than sill depths of not only the Tsugaru Strait but also the other straits, previous studies assumed that the whole water masses formed in the EJS should be isolated from the North Pacific and be consumed only within the EJS by dilution with surface water [Yanagi, 2002].

[4] Little attention has been paid to any possibility of the outflow of water below the permanent thermocline into the

\footnotetext{
${ }^{1}$ Department of Physical Oceanography, Woods Hole Oceanographic Institution, Woods Hole, Massachusetts, USA.

${ }^{2}$ Research Institute of Oceanography, School of Earth and Environmental Sciences, Seoul National University, Seoul, Korea.

${ }^{3}$ National Fisheries Research and Development Institute, Busan, Korea.
}

Copyright 2008 by the American Geophysical Union. 0094-8276/08/2007GL032981\$05.00 neighboring seas and the North Pacific except for a thin layer of the cold bottom water in the Korea Strait, originating from the northern EJS [Kim et al., 2006]. It is well known that this layer does not extend any farther out of the Korea Strait. Also, it should be noted that Kang et al. [2003] recently noted the depletion of the deep water mass and the augmentation of the intermediate waters in the EJS and Kwon et al. [2004] has shown the long-term change of the water masses. Heat and salt balances in the EJS require a priori correct water budget including any outflow of deep waters from the EJS. Thus, it is crucial to know whether any water below the thermocline finds a way out of the EJS.

[5] In this paper, we will provide the first observational evidence of intermediate water outflow through the Tsugaru Strait, using the trajectory data of profiling floats. Firstly, the detail characteristics of floats will be introduced, which are essential to demonstrate that the floats drift out with the intermediate water. Secondly, we will present a quantitative probability of which floats moved over the sill and went out of the EJS. Finally, an aspiration process will be proposed as a possible mechanism of the outflow.

\section{Data and Result}

\subsection{Profiling Float Data in the East/Japan Sea}

[6] The profiling float cycles vertically between a preset depth and the sea surface, changing its density periodically. It freely drifts for a pre-programmed time interval with the surrounding water at the preset depth (so called parking depth) and measures a temperature and salinity profile during its ascending to the sea surface. Then, while it broadcasts its data, position and time of the float at the surface are observed by satellites. It is important to know that a float drifts an unknown distance after it rises to the sea surface until its position is fixed by the satellite. Floats also drift away after their last contact with a satellite until they start to dive. Therefore, a special treatment of data such as proposed recently by Park et al. [2005] is required in order to trace the float trajectory at the parking depth accurately, since a full surface trajectory is not immediately available.

[7] More than 100 floats have been deployed in the EJS since 1996 and most of them moved around in the Ulleung Basin and the Japan Basin. Eight floats approached the Tsugaru Strait within $100 \mathrm{~km}$ from the Tappi Sill (Table 1). Five floats passed through the Tsugaru Strait and moved out into the North Pacific. We easily identify from the satellite fixes that two floats, UW229 and 10029, in Table 1 passed over the Tappi sill while they drifted at the surface. However, trajectories of the three floats in Figure 2a have no surface fixes near the sill. We will examine carefully whether those floats moved over the sill while they were at depth, indicating uplift of deep water from a depth below the sill. 


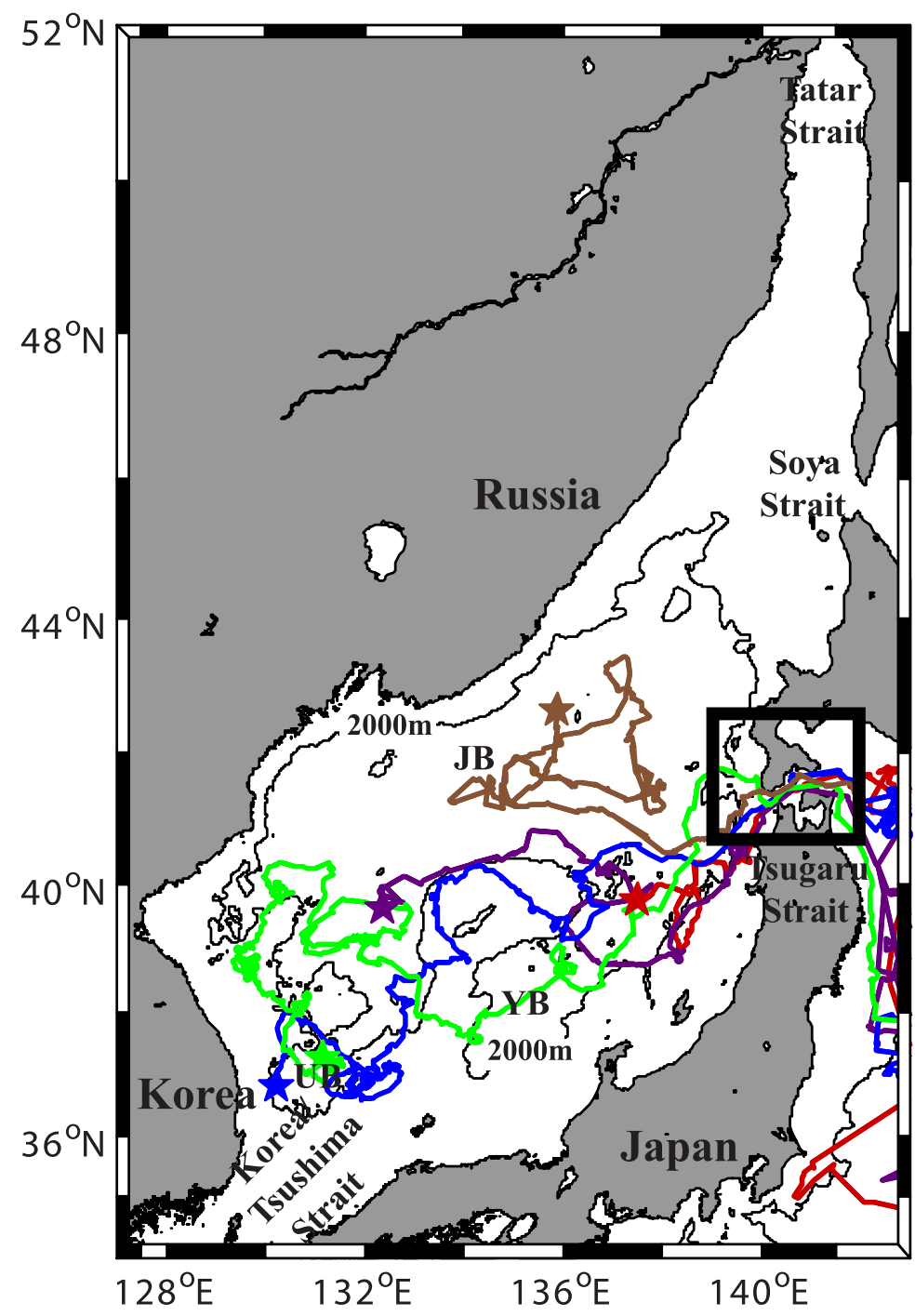

Figure 1. Trajectories of the floats which pass through the Tsugaru Strait. Red: UW213, Violet: SNU350, Blue: 08173, Brown: UW229, Green: 10029. Stars denote deployment positions. Isobath of $2000 \mathrm{~m}$ are indicated and three basins (UB: Ulleung Basin, JB: Japan Basin, YB: Yamato Basin).

[8] It is remarkable to note that all three floats, UW213, SNU350, and 08173, passed through the Tsugaru Strait in late winter. However, two other floats, UW272 and UW288 that approached the sill in summer, never went out of the EJS (Table 1).

[9] Figure 2b shows bottom topography near the Tappi Sill and schematic diagrams of float trajectories at the sea surface and at depth. In order to clarify that a float can go over the sill, we have to know the positions $\left(P_{D S}\right.$ and $\left.P_{A S}\right)$ in principle where a float reaches the depth equal to the sill depth, $140 \mathrm{~m}$, during its descent and ascent (Figure 2b). Since it is difficult to directly estimate the positions $\left(P_{D S}\right.$ and $\left.P_{A S}\right)$, we will show the possibility that the position of the Tappi Sill $\left(P_{S}\right)$ is located between $P_{D S}$ and $P_{A S}$.

\subsection{Time Information}

[10] Besides of the float trajectory data obtained by Argos satellites, additional information on timing when a float starts to dive and arrives to the sea surface can be traced using the cycle period and cycle number of each float

Table 1. Status of Floats Approaching Near the Tsugaru Strait

\begin{tabular}{|c|c|c|c|c|c|}
\hline Float ID & Date & $\begin{array}{c}\text { Shortest Distance } \\
\text { From the Tappi Sill, km }\end{array}$ & $\begin{array}{c}\text { Parking } \\
\text { Depth, dbar }\end{array}$ & $\begin{array}{l}\text { Cycle Period [(UP-time) }+ \\
\text { (DOWN-time)], hours }\end{array}$ & $\begin{array}{l}\text { Passing Through } \\
\text { the Tsugaru Strait }\end{array}$ \\
\hline SNU350 & March 12, 1998 & 33.8 & 350 & $240[10+230]$ & Over the sill \\
\hline UW213 & February 24, 2000 & 35.6 & 800 & $186[18+168]$ & Over the sill \\
\hline 08173 & March 14, 2000 & 33.0 & 750 & $120[18+102]$ & Over the sill \\
\hline UW229 & October 8, 2001 & 8.9 & 800 & $186[18+168]$ & At the surface \\
\hline 10029 & May 8, 2001 & 2.1 & 750 & $120[18+102]$ & At the surface \\
\hline UW272 & July 16,2001 & 92.7 & 800 & $186[18+168]$ & No passing \\
\hline UW288 & July 23, 2001 & 20.2 & 800 & $186[18+168]$ & No passing \\
\hline
\end{tabular}


(a)

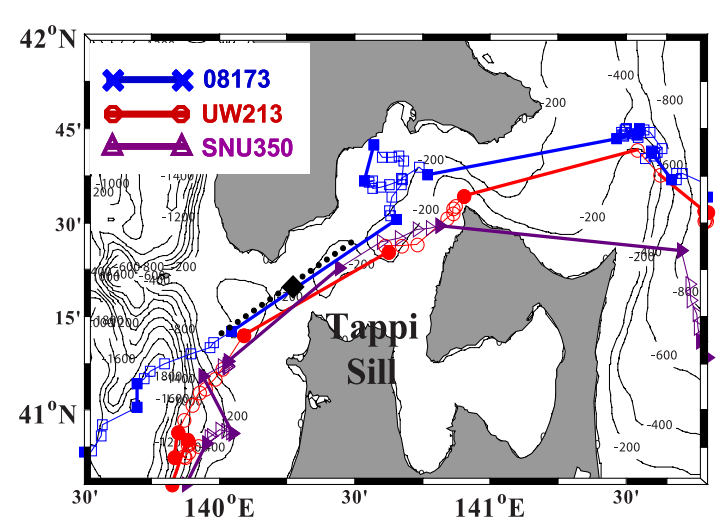

(b)

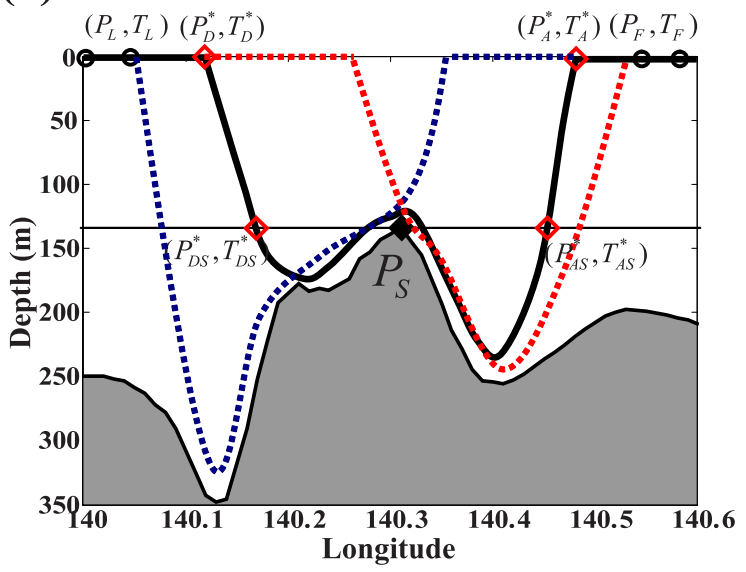

Figure 2. (a) Detailed trajectories in and around the Tsugaru Strait. Open and closed symbols are positions measured by Argos satellites and positions extrapolated using the method by Park et al. [2005]. Thick and thin lines are float trajectories at the subsurface and the sea surface. Red: UW213, Violet: SNU350, Blue: 08173. A black diamond denotes the location of the Tappi Sill. (b) A section along the black dotted line in Figure 2a and a schematic diagram of float trajectory. Black open circles are the observed fixes and red diamonds are the estimated fixes. $P_{s}$ is location of the Sill. P and T denote position and time at each fix. A black curve shows the case that a float sinks below the sill depth as it approaches the Tsugaru Strait and moves over the sill. Dotted lines in red and blue are the extreme cases that a float sinks from the sea surface or rises to the sea surface as it passes the sill depth and enters the Tsugaru Strait. The depth at the Tappi Sill is $140 \mathrm{~m}$.

according to Park et al. [2005] within an accuracy of tens of minutes, as follows:

$$
\begin{gathered}
T_{D}^{m}=T_{R}+(m-1) \Delta T_{c y c}, \quad(m=1,2,3, \cdots, M) \\
T_{A}^{m}=T_{R}+(m-1) \Delta T_{c y c}+\Delta T_{\text {down }}+\Delta T_{\text {asc }}
\end{gathered}
$$

where $T_{D}^{m}$ and $T_{A}^{m}$ are Descending-Start-Times and Ascending-End-Times at the mth cycle, $\Delta T_{c y c}$ the cycle period of float operation, $\Delta T_{\text {down }}$ the "DOWN-time" which means the duration from starting to dive to starting to ascend (Table 1), $\Delta T_{\text {asc }}$ the time from starting to ascend to arriving at the surface.

[11] We know the float ascending speed (typically $0.08 \mathrm{dbar} / \mathrm{sec}$ ) as well as the deepest depth where a float parks using previous profile data so that we can estimate $\Delta T_{\text {asc }}$. Similarly, the time $\left(T_{A}-T_{A S}\right)$ taking to ascend from $140 \mathrm{~m}$ depth to the surface can be also computed with the ascending rate, which is about 0.49 hours. Even though the time difference between $T_{D}$ and $T_{D S}$ cannot be directly computed, according to the descent rate test of Davis et al. [1992], it takes about a half hour to pass the depth of $140 \mathrm{~m}$ after a float dives to the depth.

[12] Therefore, the time differences between $T_{L}$ and $T_{D S}$ and that between $T_{A S}$ and $T_{F}\left(\Delta T_{L D S}\right.$ and $\Delta T_{A S F}$, respectively) are

$$
\begin{aligned}
\Delta T_{L D S} & =\left(T_{D S}-T_{L}\right)=\left(T_{D}-T_{L}\right)+\left(T_{D S}-T_{D}\right) \\
& \approx\left(T_{D}-T_{L}\right)+0.5 h \\
\Delta T_{A S F} & =\left(T_{F}-T_{A S}\right)=\left(T_{F}-T_{A}\right)+\left(T_{A}-T_{A S}\right) \\
& \approx\left(T_{F}-T_{A}\right)+0.5 h,
\end{aligned}
$$

which are listed in Table 2.

\subsection{Extrapolation Using Surface Trajectory of Float}

[13] The temporal integration of the surface velocities for the unknown drifting periods $\left(T_{D}-T_{L}\right.$ and $\left.T_{F}-T_{A}\right)$ could provide estimates of surfacing and diving positions as extrapolations from the surface trajectories. Closed symbols in Figure 2a show the extrapolated positions where the three floats surface and dive near the Tappi Sill according to Park et al. [2005].

[14] In fact, $P_{D S}$ and $P_{A S}$ in Figure $2 \mathrm{~b}$ are the positions that we have to know in order to demonstrate that the floats dive below the sill depth and yet go over the sill. Even though we have no further information on the vertical structure of current around the sill, we can compute the upper limit of the distance which a float may drift from $P_{D}$ to $P_{D S}$ and from $P_{A S}$ to $P_{A}$ under the assumption of homogeneous currents in depth. Maximum current speeds estimated at the surface are $0.85 \mathrm{~m} / \mathrm{s}$ for $08173,0.41 \mathrm{~m} / \mathrm{s}$ for SNU350, and $0.91 \mathrm{~m} / \mathrm{s}$ for UW213. $P_{D S}$ and $P_{A S}$ may be apart from $P_{D}$ and $P_{A}$ by only $1.5 \mathrm{~km}, 0.7 \mathrm{~km}$, and $1.6 \mathrm{~km}$ in maximum, respectively, which are more than 10 times smaller than the distance from the sill $\left(P_{S}\right)$. Therefore, it is clearly evident that all floats sink down before they reach the sill and rise up after passing over the sill.

\subsection{Probability of Float Movements Over the Tappi Sill}

[15] In this section, we investigate the quantitative probability that the three floats could move over the sill

Table 2. Parameters and Probabilities for Tracking Subsurface Trajectory of Float

\begin{tabular}{lcccc}
\hline Parameter & Float ID & SNU350 & UW213 & 08173 \\
\hline Distance & $\Delta P_{L S}$ & $33.8 \mathrm{~km}$ & $35.6 \mathrm{~km}$ & $33.0 \mathrm{~km}$ \\
& $\Delta P_{S F}$ & $26.9 \mathrm{~km}$ & $27.4 \mathrm{~km}$ & $33.5 \mathrm{~km}$ \\
Time & $\Delta T_{L D S}$ & $3.2 \mathrm{~h}$ & $6.2 \mathrm{~h}$ & $4.6 \mathrm{~h}$ \\
& $\Delta T_{A S F}$ & $4.3 \mathrm{~h}$ & $0.6 \mathrm{~h}$ & $1.2 \mathrm{~h}$ \\
Min. Velocity & $\mathrm{V}_{L D S}{ }_{\min }$ & $2.9 \mathrm{~m} / \mathrm{s}$ & $1.6 \mathrm{~m} / \mathrm{s}$ & $2.0 \mathrm{~m} / \mathrm{s}$ \\
& $\left.\mathrm{V}_{A S F}{ }^{\min }\right)$ & $1.7 \mathrm{~m} / \mathrm{s}$ & $12.7 \mathrm{~m} / \mathrm{s}$ & $7.8 \mathrm{~m} / \mathrm{s}$ \\
Probability of & $\mathrm{P}_{L D S}\left(V_{L D S} \geq V_{L D S}{ }^{m}\right)$ & $0.7 \%$ & $0.1 \%$ \\
no outflow & & & $0.7 \%$ \\
& $\mathrm{P}_{A S F}\left(V_{A S F} \geq V_{A S F}{ }_{\min }\right)$ & $0.4 \%$ & $0 \%$ & $0 \%$ \\
Probability & $\mathrm{P}=1-\left(\mathrm{P}_{L S}+\mathrm{P}_{S F}\right)$ & $99.6 \%$ & $99.3 \%$ & $99.9 \%$ \\
\hline
\end{tabular}


(a)

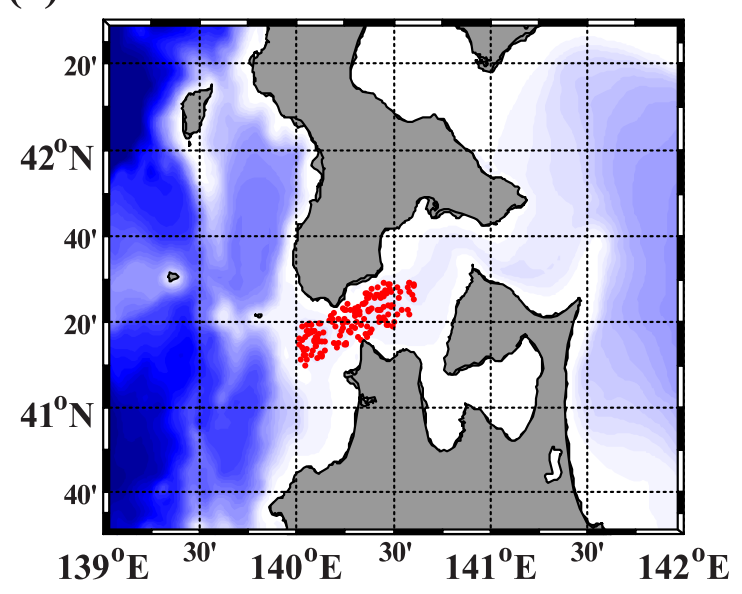

(b)

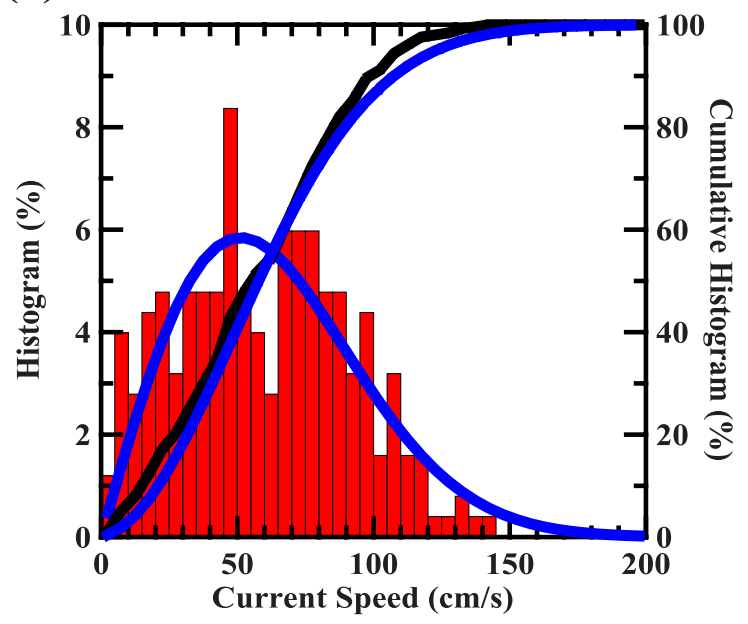

Figure 3. (a) Locations of satellite tracked drifters for estimation of current velocities. (b) Histogram of current speed near the Tsugaru Strait in a bar chart; a black dotted line present the cumulative histogram and a solid line in blue is the fitted curve with a Rayleigh function with its cumulative function as a dotted line in blue.

following the bottom. There are two extreme cases that a float may pass through the Tsugaru Strait without huddling the sill, which are indicated as dotted lines in red and blue in Figure $2 \mathrm{~b}$. For the case of the red trajectory, if $P_{D S}^{*}$ were placed at the eastern side of $P_{S}$, a float would pass through above the sill while it is ascending or it is at the surface after ascending. For the case of the blue trajectory, if $P_{A S}^{*}$ were at the western side of the $P_{S}$, a float could go by the sill while it is at the surface before descending or it is descending. Thus, showing that a float trajectory does belong to neither case, we demonstrate that the float must move over the sill if none of two extreme cases are possible in reality.

[16] At this point, $P_{D S}^{*}$ and $P_{A S}^{*}$ cannot estimated from the trajectory data directly, but a minimum drifting speed of a float can be obtained, which is required for $P_{D S}^{*}$ to be at the eastern side of the $P_{S}$ or $P_{A S}^{*}$ to be at the western side of $P_{S}$. In other words, the drifting speeds means a minimum value for a float to pass through the sill while it is at the depth shallower than the sill depth, which follows as

$$
V_{L D S}^{\min }=\frac{\Delta P_{L S}}{\Delta T_{L D S}}=\frac{\left|P_{L}-P_{S}\right|}{\Delta T_{L D S}} \text { and } V_{A S F}^{\min }=\frac{\Delta P_{S F}}{\Delta T_{L D S}}=\frac{\left|P_{S}-P_{F}\right|}{\Delta T_{A S F}} .
$$

[17] If the mean speed of currents between $P_{L}$ and $P_{S}$ $\left(V_{L D S}\right)$ exceeds the minimum speed $\left(V_{L D S}^{\min }\right)$ or that between $P_{F}$ and $P_{S}\left(V_{A S F}\right)$ exceeds $V_{A S F}^{\min }$, a float just passes through the Tsugaru Strait while it is at a depth above the sill. The distances and the minimum velocities are tabulated in Table 2 for each float.

[18] The probability $\left(\mathrm{P}_{\text {no_overflow }}\right)$ with which the overflow from depths below the sill never happens are

$$
\begin{gathered}
\mathrm{P}_{L D S}=\mathrm{P}\left(V_{L D S}>V_{L D S}^{\min }\right), \quad \mathrm{P}_{A S F}=\mathrm{P}\left(V_{A S F}>V_{A S F}^{\min }\right) \\
\mathrm{P}_{\text {no_overflow }}=\mathrm{P}_{L D S}+\mathrm{P}_{A S F} .
\end{gathered}
$$

[19] Therefore, the probability $\left(\mathrm{P}_{\text {overflow }}\right)$ that a float flows over the sill can be calculated as $\mathrm{P}_{\text {overflow }}=1-\mathrm{P}_{\text {no_overflow }}$.

[20] In order to compute the probabilities in (4a) and (4b), we utilize the current velocity data estimated from satellite tracked drifter trajectories which passed through the Tsugaru Strait from 1990 to 2005, whose drogue loss indexes have been quality-controlled by AOML (Atlantic Oceanographic and Meteorological Laboratory). The whole drifter trajectories are interpolated using the method reported by Bograd et al. [1999] and the current velocities have been calculated every 3 hours. The total number of current speed samples reaches 460 and the mean current speed is about $0.6 \mathrm{~m} / \mathrm{s}$ (Figure 3).

[21] The histogram of the surface current speeds in Figure $3 \mathrm{~b}$ is well fitted into a Rayleigh function with correlation of 0.94 . Also, the fitted Rayleigh cumulative function has a high correlation of 0.99 with the observational cumulative histogram. According to this probability distribution function, $\mathrm{P}_{L D S}$ and $\mathrm{P}_{A S F}$ in (4a) have been computed and listed in Table 2.

[22] The possibilities in Table 2 indicate that the current speeds near the Tappi Sill are mostly smaller than the minimum velocities $\left(V_{L D S}^{\min }\right.$ and $\left.V_{A S F}^{\min }\right)$. That is, the surface currents near the sill are not strong enough to let the floats pass through the sill before they dive below the sill depth, with possibility of $99.3 \% \sim 99.9 \%$. Indeed, the maximum current speed measured by the drifters reaches only about $1.4 \mathrm{~m} / \mathrm{s}$ which is substantially smaller than the minimum speeds required for a float to pass the sill depth. Therefore, we can conclude that all three floats, SNU350, UW213, and 08173 , must sink down below the sill depth and then go over the sill. There is an extremely small chance that these floats moved out of the EJS by drifting at the surface. The mean and tidal currents in the Tsugaru Strait reported by Onishi et al. [2004] typically are maximum values of $0.5 \mathrm{~m} / \mathrm{s}$ and $0.2 \sim 0.3 \mathrm{~m} / \mathrm{s}$ (for dominant constituents of M2, K1, and O1) in winter, respectively, which also support the probability estimated from surface drifters in this paper.

\section{Aspiration}

[23] An ideal model known as Bernoulli Suction which was used for the Strait of Gibraltar and the Alboran Sea 
(a)

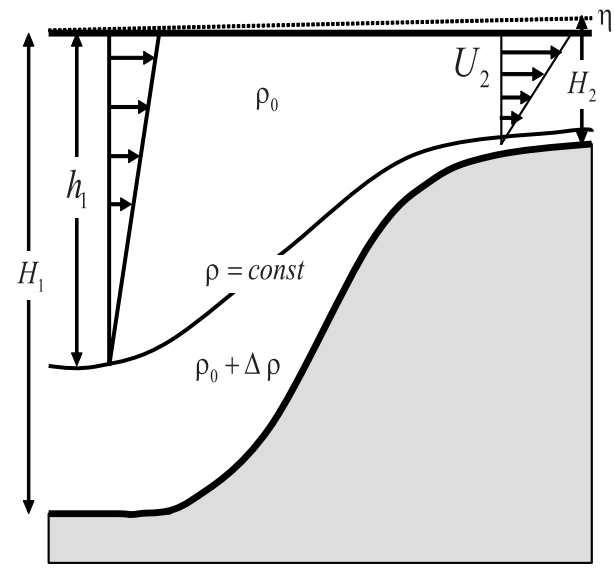

(b)

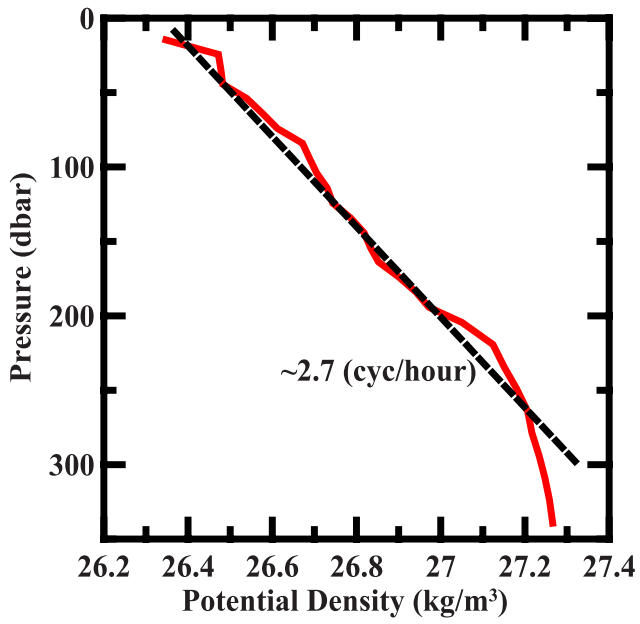

Figure 4. (a) Definition sketch for a steady, stratified flow over a sill. The density linearly increases from the surface to the bottom. (b) An example of a density in red near the Tappi Sill in March 2000. The average buoyancy frequency from the surface to $300 \mathrm{dbar}$ is about 2.7 cycle/hour (in a dotted line).

by Stommel et al. [1973] can be applied for the outflow of deep water from the EJS and its seasonal dependence. Later, Seim and Gregg [1997] introduced a simple dynamical formulation for the Bernoulli Suction under a constant stratification and showed that the depth of fluid below sill depth which could be aspirated, $h_{1}-H_{2}$, is a function of $U_{2} / N$ (Figure 4a). According to Seim and Gregg [1997] the depth of the offshore streamline $\left(h_{1}\right)$ can be formulated as

$$
h_{1}=\frac{1}{2} H_{2}+\left(\frac{1}{4} H_{2}^{2}+\frac{U_{2}^{2}}{N^{2}}\right)^{1 / 2},
$$

where $N^{2}=g \Delta \rho / \rho_{0} H_{1}, g$ is the gravitational acceleration, $\rho_{0}$ the surface density, and $\Delta \rho$ is the density difference from top to bottom in the deep basin.

[24] Figure 4b is an example of potential density profile right near the Tappi Sill which was obtained in March, 2000, the late winter. Average buoyancy frequency (N) is about $5 \times 10^{-3} \mathrm{~s}^{-1}$. Supposing that current speed in the strait is about $1.4 \mathrm{~m} / \mathrm{s}$ which is the maximum of the current velocities in Figure $3, h_{1}$ is computed as about $380 \mathrm{~m}$. So, fluid deeper by $240 \mathrm{~m}$ than the sill depth of $140 \mathrm{~m}$ can go over the sill and enter the Tsugaru Strait. On the other hand, the typical buoyancy frequency in summer reaches about $2 \times 10^{-2} \mathrm{~s}^{-1}$, which is 4 times larger than that in winter, and $h_{1}$ becomes about $170 \mathrm{~m}$ under the same speed of surface current. Therefore, the late winter is the most favorable season for deep water flows out to the North Pacific because of the weak vertical stratification.

[25] As mentioned in section 2.1, the floats are designed to follow isobaric surfaces. So, the floats of UW213 and 08173 with the parking depth of $800 \mathrm{dbar}$ might be denser than the surrounding water even though they grounded in front of the sill at the ocean bottom of $300 \mathrm{~m}$ depths (in-situ density at 300 dbar: $1028.7 \mathrm{~kg} / \mathrm{m}^{3}$; density at 800 dbar: $\left.1031.0 \mathrm{~kg} / \mathrm{m}^{3}\right)$. Also there is a possibility that some sediment like mud could be attached on surface of the float (D. Swift, personal communication, University of Washington, 2007). It should be noted that these behaviors could make a float denser than expected and prevents it from going over the sill with the surrounding fluid. However, all floats move to shallower regions (shallower than about $300 \mathrm{~m}$ ) while they are at the surface before going over the sill. Indeed, the subsurface drifts of the floats (UW213 and SNU350) near the mouth of the Tsugaru Strait either following isobaths or hardly move around at depth before moving toward the sill at the surface. Even though the floats may be heavier than the surrounding bottom water, it is conjectured that they may slide or walk over the ocean bottom to traverse the sill by advection within strong currents at the bottom.

[26] Acknowledgments. We thank Steve Riser and Dana Swift for kindly providing profiling float data and valuable discussion. In addition special thanks go to Ray Schmitt and Young-Oh Kwon for their comments and discussions. This study was partly supported by the project of ARGO for Data Assimilation project in the Meteorological Research Institute/KMA, the Korea EAST-1(East Asian Seas Time series East Sea) Program from the Ministry of Maritime Affairs and Fisheries, and Korea Research Foundation Grant (KRF-2005-070-C00142). The first author was partly supported by the Ministry of Education, Korea, through the BK21 project.

\section{References}

Bograd, S. J., A. B. Rabinovich, R. E. Thomson, and A. J. Eert (1999), On duty cycles and interpolation schemes for WOCE-SVP satellite-tracked drifters, J. Atmos. Oceanic Technol., 16, 893-904.

Davis, R. E., D. C. Webb, L. A. Regier, and J. Dufour (1992), The Autonomous Lagrangian Circulation Explorer (ALACE), J. Atmos. Oceanic Technol., 9, 264-285.

Kang, D., S. Park, Y. Kim, K. Kim, and K. Kim (2003), A moving-boundary box model (MBBM) for oceans in change: An application to the East/Japan Sea, Geophys. Res. Lett., 30(6), 1299, doi:10.1029/2002GL016486.

Kim, K., K.-R. Kim, Y.-G. Kim, Y.-K. Cho, D.-J. Kang, M. Takematsu, and Y. Volkov (2004), Water masses and decadal variability in the East Sea (Sea of Japan), Prog. Oceanogr., 61, 157-174.

Kim, Y. H., Y.-B. Kim, K. Kim, K.-I. Chang, S. J. Lyu, Y.-K. Cho, and W. J. Teague (2006), Seasonal variation of the Korea Strait Bottom Cold Water and its relation to the bottom current, Geophys. Res. Lett., 33, L24604, doi:10.1029/2006GL027625. 
Kwon, Y.-O., K. Kim, Y.-G. Kim, and K.-R. Kim (2004), Diagnosing longterm trends of the water mass properties in the East Sea (Sea of Japan), Geophys. Res. Lett., 31, L20306, doi:10.1029/2004GL020881.

Onishi, M., et al. (2004), Winter transport and tidal current in the Tsugaru Strait, Bull. Fish. Sci. Hokkaido Univ., 55(2), 105-119.

Park, J. J., K. Kim, B. A. King, and S. C. Riser (2005), An advanced method to estimate deep currents from profiling floats, J. Atmos. Oceanic Technol., 22, 1294-1304.

Seim, H. E., and M. C. Gregg (1997), The importance of aspiration and channel curvature in producing strong vertical mixing over a sill, J. Geophys. Res., 102(C2), 3451-3472.
Stommel, H., H. Bryden, and P. Mangelsdorf (1973), Does some of the Mediterranean outflow come from great depth?, Pure Appl. Geophys., $105,879-889$.

Yanagi, T. (2002), Water, salt, phosphorus and nitrogen budgets of the Japan Sea, J. Oceanogr., 58, 797-804.

K. Kim, Research Institute of Oceanography, School of Earth and Environmental Sciences, Seoul National University, San 56-1, Shillim-dong, Kwanak-gu, Seoul 151-742, Korea. (kuhkim@snu.ac.kr)

J. J. Park, Department of Physical Oceanography, Woods Hole Oceanographic Institution, Woods Hole, MA 02543, USA.

J.-Y. Yang, National Fisheries Research and Development Institute, 408-1, Shirang-ri, Gijang-up, Gijang-gun, Busan, 619-902, Korea. 